\title{
A brief summary of the progress on the EFDA tungsten materials program
}

\begin{abstract}
M. Rieth ${ }^{a}$, S.L. Dudarev ${ }^{b}$, S.M. Gonzalez de Vicente ${ }^{c}$, J. Aktaa ${ }^{a}$, T. Ahlgren ${ }^{\text {, }}$ S. Antusch ${ }^{\mathrm{a}}$,

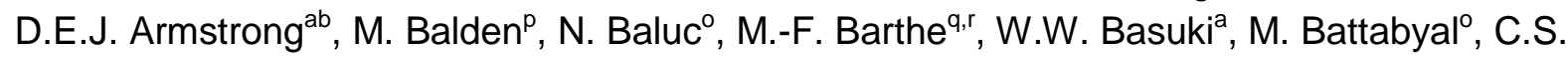
Becquart $^{\mathrm{t}}$, D. Blagoevai, H. Boldyryeva ${ }^{\mathrm{h}}$, J. Brinkmann ${ }^{\mathrm{p}}$, M. Celino ${ }^{\mathrm{k}}$, L. Ciupinski ${ }^{\mathrm{e}}$, J.B. Correia $^{m}$, A. De Backer ${ }^{t}$, C. Domain ${ }^{x}$, E. Gaganidze ${ }^{a}$, C. Garcia-Rosales ${ }^{n}$, J. Gibson $^{\mathrm{ab}}$, M.R. Gilbert $^{b}$, S. Giusepponik ${ }^{k}$ B. Gludovatz ${ }^{j}$, H. Greuner ${ }^{p}$, K. Heinola ${ }^{\mathrm{s}}$, T. Höschen ${ }^{\mathrm{p}}$, A. Hoffmann ${ }^{z}$, N. Holstein ${ }^{a}$, F. Koch ${ }^{p}$, W. Krauss ${ }^{a}$, H. Li', S. Lindig ${ }^{p}$, J. Linke ${ }^{d}$, Ch. Linsmeier ${ }^{p}$, P. LopezRuiz $^{n}$, H. Maier ${ }^{p}$, J. Matejicek ${ }^{h}$, T.P. Mishra ${ }^{p}$, M. Muhammed', A. Munoz ${ }^{f}$, M. Muzyk ${ }^{\mathrm{e}}$, K. Nordlund $^{\mathrm{s}}$, D. Nguyen-Manh ${ }^{\mathrm{b}}$, J. Opschoor ${ }^{\mathrm{w}}$, N. Ordas ${ }^{\mathrm{n}}$, T. Palacios ${ }^{y}$, G. Pintsuk ${ }^{\mathrm{d}}$, R. Pippan $^{\mathrm{j}}$, J. Reiser ${ }^{a}$, J. Riesch ${ }^{p}$, S.G. Roberts ${ }^{\mathrm{ab}}$, L. Romaner ${ }^{\mathrm{ac}}$, M. Rosin' ski $^{\mathrm{e}}$, M. Sanchez $^{\mathrm{g}}, \mathrm{W}$. Schulmeyer $^{\mathrm{z}}$, H. Traxler ${ }^{\mathrm{z}}$, A. Urena ${ }^{\mathrm{g}}$, J.G. van der Laan ${ }^{\mathrm{aa}}$, L. Veleva ${ }^{0}$, S. Wahlberg', M. Walter $^{\mathrm{a}}$, T. Weber ${ }^{\mathrm{a}}$, T. Weitkamp ${ }^{\mathrm{u}, \mathrm{v}}$, S. Wurster ${ }^{j}$, M.A. Yar', J.H. You ${ }^{\mathrm{p}}$, A. Zivelonghi $^{\mathrm{p}}$
\end{abstract}

a Karlsruhe Institute of Technology, Institute for Applied Materials, Karlsruhe, Germany

b EURATOM/CCFE Fusion Association, Culham Science Centre, Abingdon OX14 3DB, UK

c EFDA-Close Support Unit, Garching, Germany

d Forschungszentrum Jülich, EURATOM Association, Germany

e Faculty of Materials Science and Engineering, Warsaw University of Technology, Woloska 141, 02-507 Warsaw, Poland

f Departamento de Física, Universidad Carlos III, Avda. de la Universidad 30, 28911 Leganés, Madrid, Spain

9 Departamento de Ciencia e Ingeniería de Materiales, ESCET, Universidad Rey Juan Carlos, C/Tulipán s/n 28933 Móstoles, Madrid, Spain

h Institute of Plasma Physics, Za Slovankou 3, 18200 Praha, Czech Republic

i NRG, Nuclear Research \& Consultancy Group, Petten, The Netherlands

j ÖAW, Erich Schmid Institute of Materials Science, Leoben, Austria

k ENEA, C.R. Casaccia, Via Anguillarese 301, 00123 Rome, Italy

I KTH, Department of Functional Materials, Stockholm, Sweden

m Association EURATOM-IST, Instituto de Plasmas e Fusão Nuclear - Laboratório Associado, Instituto Superior Técnico, Universidade Técnica de Lisboa, Portugal

n CEIT and Tecnun (University of Navarra), Paseo de Manuel Lardizabal 15, 20018 San Sebastian, Spain

- Centre de Recherches en Physique des Plasmas, CRPP EPFL - Materials, 5232 Villigen/PSI, Switzerland

p Max-Planck-Institut für Plasmaphysik, EURATOM Association, Garching, Germany 
CNRS, UPR3079 CEMHTI, 1D Avenue, de la Recherche Scientifique, 45071 Orléans Cedex 2, France

r Université d'Orléans, Polytech ou Faculté des Sciences, Avenue du Parc Floral, BP 6749, 45067 Orléans Cedex 2, France

s University of Helsinki, Department of Physics, Helsinki, Finland

t Unité Matériaux et Transformations, UMR 8207, 59655 Villeneuve d'Ascq, France

u ESRF Grenoble, 6 Rue Jules Horowitz, 38043 Grenoble, France

v Synchrotron Soleil, L'Orme des Merisiers, St. Aubin, 91190 Gif-sur-Yvette, France

w ECN, Energy Research Centre of the Netherlands, Petten, The Netherlands

x EDF R\&D, Les Renardières, 77250 Moret sur Loing, France

y Universidad Politécnica de Madrid, Materials Science Department, Madrid, Spain

z PLANSEE SE, Metallwerk-Plansee-Strabe 71, 6600 Reutte, Austria

aa Consultant, 1831 AD 25, The Netherlands

ab Department of Materials, University of Oxford, UK

ac Atomistic Modelling and Design of Materials, Montan Universität Leoben, Franz-JosefStraße 18, A-8700 Leoben, Austria

\section{Abstract}

The long-term objective of the European Fusion Development Agreement (EFDA) fusion materials programme is to develop structural and armor materials in combination with the necessary production and fabrication technologies for reactor concepts beyond the International Thermonuclear Experimental Reactor. The programmatic roadmap is structured into four engineering research lines which comprise fabrication process development, structural material development, armor material optimization, and irradiation performance testing, which are complemented by a fundamental research programme on "Materials Science and Modelling." This paper presents the current research status of the EFDA experimental and testing investigations, and gives a detailed overview of the latest results on materials research, fabrication, joining, high heat flux testing, plasticity studies, modelling, and validation experiments.

Corresponding author. Michael Rieht

Karlsruhe Institute of Technology - Campus Nord, Institute for Applied Materials, P.O. Box 3640, 76021 Karlsruhe, Germany.

Tel.: +49 7216082 2909; fax: +49 7216082 4567. E-mail address: Michael.rieth@kit.edu (M. Rieth). 


\section{Introduction}

The use of tungsten and tungsten alloys for the helium cooled divertor and possibly for the protection of the helium cooled first wall in reactor design beyond the International Thermonuclear Experimental Reactor (ITER) has been discussed and investigated for several years (see, for example, [1-8]). The structure of the Tungsten and Tungsten Alloys (WWALLOY) programme of the European Fusion Development Agreement (EFDA) Topical Group on fusion materials can be found in [9], which also includes a first review of the activities. However, the main objective is still to develop and demonstrate possible applications and to identify limitations for the use of tungsten and tungsten-based materials in future fusion reactors. These materials will differ significantly from ITER in so far as they will come with a high neutron irradiation dose and transmutation rates. But even neglecting irradiation effects (due to large gaps in the database), there are still unsolved problems related to the use and properties of tungsten materials. In the following, results, conclusions, and outlooks are summarized for each of the WWALLOY program's main subtopics, which are (1) fabrication, (2) structural W materials, (3) W shield materials, and (4) materials science and modelling.

\section{Fabrication}

The current helium cooled finger design [3] has been used so far as a reference for component fabrication issues. The most important questions in this field are: What mass fabrication methods could be applied for the thimbles and possibly for the tiles? Are there feasible processes for $\mathrm{W}-\mathrm{W}$ and $\mathrm{W}$-steel joints?

\subsection{Fabrication process development}

Due to its unfavorable grain orientation, rod material cannot be used to machine a thimble by turning or milling. The most promising machining route consists of deep drawing of a $\mathrm{W}$ plate, which results in grains that follow the contour. It is important that for components made of tungsten 'grain boundary alignment' is a highly necessary tool to create the best possible arrangement for external forces acting on the weak grain boundaries. Therefore, it would be necessary to deep draw a thimble from a $1 \mathrm{~mm}$ tungsten plate. Consequently, the tungsten plate material which has been chosen for deep drawing is unalloyed $99.97 \%$ pure tungsten (standard rolled commercial grade) with a thickness of $1 \mathrm{~mm}$. This commercially available material was produced by PLANSEE SE, Reutte/Austria. In a deep drawing tool, tungsten blanks with diameters of $23 \mathrm{~mm}$ and $26 \mathrm{~mm}$ were deep drawn successfully in a vacuum (about $10^{-5} \mathrm{mbar}$ ) at $873 \mathrm{~K}\left(600{ }^{\circ} \mathrm{C}\right)$ with a strain rate of $0.1 \mathrm{~mm} / \mathrm{min}$. Micrographs of the cross-section reveal that the grains follow the contour of the thimble. For more details on the deep drawing assessment see [10].

Powder injection molding (PIM) was investigated as mass fabrication option for the tungsten armor tiles which had to be joined to the thimbles. A new tool design enabled the first production of such tiles via PIM (pre-sintering at $1873 \mathrm{~K}\left(1600{ }^{\circ} \mathrm{C}\right)$ for $2 \mathrm{~h} \mathrm{in} \mathrm{H}_{2}$ atmosphere followed by a hot isostatic pressing (HIP) cycle with $250 \mathrm{MPa}$ at $1923 \mathrm{~K}\left(1650{ }^{\circ} \mathrm{C}\right)$ for $3 \mathrm{~h}$ in Ar atmosphere). With that, the final parts showed $98.6-99 \%$ of the theoretical density, Vickers hardnessof $457 \mathrm{HV} 0.1$, and a grain size of approximately $5 \mu \mathrm{m}$ [11a]. 
According to the design, the tiles (pure tungsten) and the mechanical machined thimbles (WL10) have to be joined together by brazing, which would have several drawbacks and would be time intensive. As a mass production alternative, two-component tungsten PIM was investigated using different pure and alloyed $\mathrm{W}$ powders. This would allow the joining of two different materials in one process - in this case tungsten and oxide dispersion strengthened (ODS) tungsten alloys. Therefore, a two-step process to produce a single part has been developed and first preliminary two-component PIM tests have been performed. The compositions of the finished disks after heat-treatment (pre-sintering at $2073 \mathrm{~K}\left(1800{ }^{\circ} \mathrm{C}\right), 2$ $\mathrm{h}, \mathrm{H}_{2}$ and HIP at $2373 \mathrm{~K}\left(2100{ }^{\circ} \mathrm{C}\right), 3 \mathrm{~h}, 250 \mathrm{MPa}$, Ar atmosphere) are $\mathrm{W}$ and $\mathrm{W}-2$ wt. $\% \mathrm{La}_{2} \mathrm{O}_{3}$ as well as $\mathrm{W}$ and $\mathrm{W}-2$ wt. $\% \mathrm{Y}_{2} \mathrm{O}_{3}$. In the cross-section of the finished disks, neither cracks nor voids could be detected in the joining zone, which is encouraging for further investigations.

\subsection{Joining and transitions from steel to tungsten}

One result of the investigations for using electrochemistry for brazing layers fabrication is that the brazing material can be built up from a sequence of electrochemically deposited layers. Growing of galvanic layers from suitable low temperature liquid electrolytes depends on the transported charge and thus can easily be controlled over a wide range by current flow and/or deposition time. Typical elements which can be used for joining may range from $\mathrm{Ti}, \mathrm{V}$ via $\mathrm{Ni}$, Fe up to $\mathrm{Pd}$, and $\mathrm{Cu}$. Further, interlayers with an active functionality which interact with both bulk components and filler could be useful for the joining process. For both joints W-W and W-EUROFER, demonstrators were successfully fabricated and analyzed by metallurgical and physical methods.

An alternative to brazing tungsten to steel parts is diffusion bonding. Investigations were performed on the applicability of this technique using vanadium interlayers. Since steel (in this case EUROFER) contains some carbon, the problem is to prevent the formation of very brittle vanadium-carbide layers. It was demonstrated that diffusion bonding at only $973 \mathrm{~K}$ $(700 \mathrm{C})$ can be successfully performed with a minimal alteration of the microstructure of the base materials.

While graded transition joints from steel to tungsten probably cannot be used for structural applications, they might nevertheless be useful for attaching the shield (tungsten) to the first wall (EUROFER). Magnetron sputtering, vacuum plasma, laser spraying, and hot pressing processes were applied for this purpose. Laser spraying succeeded in producing dense tungsten-steel composites with uniform distribution of the phases. However, the full-tungsten surface layer retained some porosity. Among the advantages of this technique are limited heat input to the coated part and the ability to coat complex shapes. Plasma spraying offers the advantage of easy control of compositional profile and the ability to cover large areas. Relatively low thermal conductivity, due to the lamellar microstructure and porosity, remains the main limitation of this technique. Investigations are underway concerning process modifications and post-treatment with the aim of improved conductivity. So far, drawbacks have been identified by the limitation of the process temperature due to porosity, grain coarsening, and formation of intermetallic phases and the restricted scalability of the whole fabrication to large-scale components [11a-g].

For brazing tungsten, pure titanium, $\mathrm{Ti}-\mathrm{Fe}$, and ternary $\mathrm{Ti}-\mathrm{Cr}-\mathrm{Fe}$ filler materials were used to fabricate the according joints. From the analysis of the microstructure it could be seen that 
most joints lead to cracks, pores, or diffusion layers. Ongoing mechanical tests have to show whether titanium based brazing materials can really be used for joining tungsten parts.

Yet another alternative to brazing is the use of pulse plasma sintering/welding. This method was applied to join tungsten tiles directly to WL10 thimbles. The first microstructural examinations have shown areas of perfect joints but also some gaps. Pulse plasma sintering was also used to join a WL10 thimble to a EUROFER pipe. For the circumferential joint, a $100 \mu \mathrm{m}$ iron foil was placed between the thimble/pipe and the conical sleeve. Here also the microstructural examinations have shown some gaps. Nevertheless, this seems to be a promising process worthy of further improvement by ongoing investigations and developments.

\section{Structural tungsten materials}

The main requirements on tungsten materials for structural divertor applications comprise properties like high thermal conductivity, high temperature strength and stability, high recrystallization temperature, and enough ductility [12b-d] for an operation period of about 2 years under enormous neutron load. The investigations during the recent years have shown that creep strength and recrystallization can be improved with little effect on thermal conductivity using dispersed oxides such as lanthana or yttria, which stabilize the grains. The intrinsic brittleness of tungsten (measured by Charpy tests), however, cannot be improved significantly by oxide dispersion. In contrary, intercrystalline fracture is enhanced even more.

Furthermore, it was shown that due to its distinct anisotropic microstructure tungsten rod material is useless for most structural applications, for example, pipe fabrication. Plates show also anisotropic behavior. Nevertheless, with thin plates the microstructure can very easily be aligned to the contour of the according part (e.g., by bending or deep drawing), which leads to the optimum stress distribution and, therefore, to the best possible fracture behavior [12a].

However, the brittleness (measured by Charpy or by fracture mechanics tests) of tungsten materials is still the main problem for their use as structural materials. And due to neutron irradiation, the shift of ductile-to-brittle transition temperature (DBTT) can be in the range of several hundred degrees. Therefore, the most pressing question is: How can DBTT significantly be decreased?

\subsection{Ductilization}

In principle, three ductilization strategies were followed in the present program: (1) alloying/solid solution, (2) nanostructuring, and (3) producing composite materials.

So far only rhenium is known to improve the ductility of tungsten by solid solution, but its use for fusion energy applications has been ruled out for various reasons (e.g., cost, irradiation embrittlement). Iridium too is sometimes mentioned in literature to have a similar effect, though it is even more expensive. This leaves only tantalum, vanadium, molybdenum, and titanium, which also form a solid solution with tungsten. Round blanks of $\mathrm{W}-1 \% \mathrm{Ta}, \mathrm{W}-5 \% \mathrm{Ta}$, $\mathrm{W}-5 \% \mathrm{~V}, \mathrm{~W}-25 \% \mathrm{Mo}$, and $\mathrm{W}-50 \% \mathrm{Mo}$ have been produced by PLANSEE (sintered in hydrogen atmosphere and forged to a deformation degree of 80\%). Charpy tests in the temperature range of $673-1373 \mathrm{~K}\left(400-1100{ }^{\circ} \mathrm{C}\right)$ in vacuum have shown, that compared to 
pure tungsten, the DBTT of all alloys is higher, i.e., they are more brittle. Therefore, it is assumed that tungsten cannot be ductilized by solid solution, except with rhenium (or maybe iridium). As a last option, however, the effect of titanium has still to be investigated.

Nanostructuring of tungsten and tungsten alloys has been investigated in the past by severe plastic deformation (e.g., by high pressure torsion, HPT). But these processes are not suitable for producing industrial scale semi-finished products. That's why in the present programme powder metallurgical fabrication routes were followed, which include mechanical alloying and HIP and/or hot/cold forming.

The investigated materials comprise pure $\mathrm{W}, \mathrm{W}-\mathrm{Ti}, \mathrm{W}-\mathrm{V}$, and $\mathrm{W}-\mathrm{Ta}$ alloys. In some cases they are reinforced with $\mathrm{Y}_{2} \mathrm{O}_{3}, \mathrm{La}_{2} \mathrm{O}_{3}$, or TiC particles (see, for example, [13]). It was found that all the materials are composed of small grains, with sizes ranging between 20 and 500 $\mathrm{nm}$, and show a high density $\left(5.4-6.9 \times 10^{22} \mathrm{~m}^{3}\right)$ of small $\mathrm{Y}_{2} \mathrm{O}_{3}$ or TiC particles, with sizes between 1 and $50 \mathrm{~nm}$. In the case of $\mathrm{W}-\mathrm{Y}$ materials, all the $\mathrm{Y}$ transformed into $\mathrm{Y}_{2} \mathrm{O}_{3}$ during mechanical alloying, due to the high amount of $O$ (around 1 wt.\%) present in the milled powders, which is beneficial for reducing the excess $O$ content in the materials. All the materials also contain a residual porosity of a few percent, which is typical of materials compacted by a HIP cycle, and they exhibit high strength and a promising radiation resistance. However, in spite of their small grain sizes, they are very brittle and show poor fracture properties at low to moderate temperatures. For instance, the DBTT of the $\mathrm{W}-\mathrm{Y}, \mathrm{W}-$ $\mathrm{Ti}$, and $\mathrm{W}-\mathrm{V}$ materials was found to be typically between $1373 \mathrm{~K}\left(1100{ }^{\circ} \mathrm{C}\right)$ and $1473 \mathrm{~K}$ $\left(1200{ }^{\circ} \mathrm{C}\right)$, which can be considered additional proof of the previously mentioned effect of solid solution elements. Due to the fabrication route, missing mechanical working and/or an increased impurity level could also explain this severe brittleness.

However, a new $\mathrm{W}-2 \% \mathrm{Y}_{2} \mathrm{O}_{3}$ material was produced by sintering and hot forging in collaboration with PLANSEE [14]. The relative density of the ingot was found equal to $99.3 \%$. The material appears composed of grains with a mean size around $1 \mu \mathrm{m}$ and also contains $\mathrm{Y}_{2} \mathrm{O}_{3}$ particles with sizes ranging between 300 and $900 \mathrm{~nm}$. Fracture mechanical three-point bending and tensile tests showed that the material is fully ductile in the temperature range of $573-1273 \mathrm{~K}\left(300-1000^{\circ} \mathrm{C}\right)$, with the total elongation ranging between about $4 \%$ and $10 \%$.

An alternative route to fabricate nanostructured tungsten-based materials is by chemical powder metallurgical methods. A precursor powder containing the required elemental composition can be prepared in aqueous solution from atomic or molecular level under controlled conditions to engineer particle characteristics such as size, composition, and structure. The obtained precursor is thereafter further reduced under hydrogen and sintered into the final tungsten composite. Several tungsten materials containing $1 \% \mathrm{La}_{2} \mathrm{O}_{3}$ or $\mathrm{Y}_{2} \mathrm{O}_{3}$ have been produced using an early development of the method [15] in which La- or Y-ions mainly occurred on the surface of the precursor particle, resulting in an inhomogeneous distribution of the doping elements in the sintered material. In a recent development, precursor powders are fabricated under certain solution conditions where the particle growth could be controlled to produce uniformly yttrium doped nanosized tungsten oxides. The starting material, ammonium paratungstate with a particle size of 30-100 $\mu \mathrm{m}$, is transformed under acid solution conditions via a solvent mediated process into precursor powders with a crystallite size of less than $10 \mathrm{~nm}$. These powders have been reduced under hydrogen to nanostructured tungsten-ODS powders $\left(1-5 \% \mathrm{Y}_{2} \mathrm{O}_{3}\right)$ and sintered to ultrafine- or fine-grained tungsten composites with up to $95 \%$ relative density, uniform with respect both to 
microstructure and composition. The method can produce extremely uniform materials, with respect to morphology as well as composition.

To enhance fracture toughness of tungsten, the concept of fiber reinforced composites was applied. A new concept of tungsten-fiber reinforced tungsten composites ( $W_{f} / W_{m}$-composite) relies on pure tungsten as an element for the composite. The applied toughening mechanism is analogous to those being used in fiber reinforced ceramic matrix composites, the so-called pseudo toughness. A controlled crack deflection at the engineered fiber/matrix interfaces leads to internal energy dissipation by interface debonding and friction. Local stress can be reduced and thus the global fracture toughness is improved [16]. Recently, the pseudo toughness behavior was shown in a three point bending test (according to ASTM E399). The specimen contained about 90 unidirectionally orientated fibers resulting in a fiber volume fraction of about $25 \%$. Whereas the pure chemical vapor deposited tungsten catastrophically fails after crack initiation, the $\mathrm{W}_{\mathrm{f}} / \mathrm{W}_{\mathrm{m}}$-composite shows stable crack propagation and a rising $R$-curve. The fracture toughness, KQ, in that area rises from 7.1 (crack initiation) to 17.5 (load drop). As determining the crack length is difficult in a composite, the initial, artificial crack length was taken for calculating $\mathrm{KQ}$. At a certain point during the experiment a severe event, e.g. multiple fiber fracture, leads to a large load drop, but not to a full fracture. The sample still can bear load. Further loading causes toughening effects like fiber pull-out, internal friction, or minor fractures. These lead to large energy dissipation and thus a large improvement in fracture toughness.

In a second concept, the brittle $\mathrm{W}$ matrix is reinforced by short fibers of tantalum (initially 100 $\mu \mathrm{m}$ diameter wire). As $\mathrm{Ta}$ is more ductile than $\mathrm{W}$, it can divert or stop cracks propagating in the $\mathrm{W}$ matrix. Elastic and plastic deformations of the reinforcing fibers absorb the elastic energy released by the propagating crack. The major difficulty with this concept is the interdiffusion between the $\mathrm{W}$ matrix and the Ta fibers during sintering at temperatures of $1773-1873 \mathrm{~K}\left(1500-1600{ }^{\circ} \mathrm{C}\right)$. One approach is to use spark plasma sintering to reduce the duration of exposure to high temperature to less than $5 \mathrm{~min}$ and still achieve $90 \%$ densification in a single operation. Service temperatures below the recrystallization temperature (about $1373 \mathrm{~K}, 1100{ }^{\circ} \mathrm{C}$ ) induce negligible interdiffusion in the composite, especially in the case of Ta fibers [17].

A third approach considers a tungsten laminate material which is fabricated of tungsten foils brazed by copper. The composite strategy seems to be rather promising with respect to improving fracture toughness.

\subsection{Characterization for $W$ data base}

For clear comparability, all the produced materials have to be characterized by basic, standardized methods, which are (1) DBTT measurement either by Charpy or by fracture mechanics tests, (2) creep/tensile/indentation tests up to $1573 \mathrm{~K}\left(1300{ }^{\circ} \mathrm{C}\right)$, (3) thermal conductivity measurements, (4) determination of recrystallization temperature, and (5) microstructure and fracture analysis. Within the present EFDA programme, commercial grade tungsten materials are used to establish a database for future recording of the progress in material development. As an example, fracture toughness of a round blank of pure tungsten where the specimens were oriented longitudinally $(L-R)$, radially $(R-L)$ and circumferentially (C-R) was investigated intensively (see $[18,19])$. 


\section{Tungsten armor materials}

The range of operating temperatures and load conditions (pulse, fatigue, shock, flux, etc.) depends strongly on the power plant design and cannot be exactly specified yet. However, the lowest shield temperatures can be expected to be somewhat higher than the maximum coolant temperature, i.e., about $1073-1173 \mathrm{~K}\left(800-900^{\circ} \mathrm{C}\right)$ in the case of the helium cooled finger design and about $773 \mathrm{~K}\left(500{ }^{\circ} \mathrm{C}\right)$ for the blanket's first wall. The maximum temperatures will certainly be higher than $1973 \mathrm{~K}\left(1700^{\circ} \mathrm{C}\right)$ on the divertor armor surface.

With that, the most important questions in this line of research are: How can the sputtering rates and surface modification mechanisms of tungsten armor materials be simulated by existing test facilities? Are there optimal tungsten materials for armor applications? Is it possible to utilize oxidation resistant tungsten alloys to increase safety in case of air ingress in accident scenarios?

\subsection{Heat flux, shock, and high temperature testing}

Besides basic material characterization in an extended high temperature range (including thermal fatigue), thermal shock tests in the operation relevant parameter range (JUDITH electron beam facility, FZ Jülich [20]) and thermal fatigue tests under hydrogen and/or helium neutral beam loading (GLADIS, IPP, Garching [21,22]) with divertor relevant power fluxes were carried out.

The thermal shock effect of possible edge localized modes in the plasma on various new metal injection molded armor materials was simulated in the JUDITH facility. The incident power flux was varied between 0.19 and $1.13 \mathrm{GW} / \mathrm{m}^{2}$, the test temperatures were room temperature, $473 \mathrm{~K}\left(200^{\circ} \mathrm{C}\right)$, and $673 \mathrm{~K}\left(400^{\circ} \mathrm{C}\right)$, and the specimens were loaded with 100 (in some cases even 1000) pulses with a duration of $1 \mathrm{~ms}$. The most promising material so far is $\mathrm{W}-1$ vol. $\% \mathrm{Y}_{2} \mathrm{O}_{3}$, which has shown no crack formation, while pronounced cracking is observed in $\mathrm{W}-5$ vol. $\% \mathrm{Y}_{2} \mathrm{O}_{3}$ and $\mathrm{W}-\mathrm{Ta}$ materials under similar loadings. Moreover, the JUDITH 2 facility was used for investigations on high cycle thermal shock tests (up to $10^{6}$ cycles) with the tungsten reference material. Initial results revealed that surface roughening inevitably leads to crack development and subsequently to melting at crack edges.

A comparative study of surface morphology changes of $\mathrm{W}$ materials under cyclic hydrogen and helium beam loading was performed at the GLADIS facility at IPP Garching. In the frame of the European material development programme for DEMO, W containing 5\% Ta as well as uniaxially forged ultra-high purity $\mathrm{W}$, and powder injection molded tungsten were assessed. Complementary to thermo-mechanical investigation of the high heat flux behavior of $\mathrm{W}$ as plasma facing material, the investigation of the morphology modification, occurring during heat loading using $\mathrm{H}$ and He particles, which simulates the expected steady-state DEMO divertor operation conditions, is indispensable to the development of reliable armor materials. Effects of erosion, gas retention, and void formation depend on both the loading conditions and the operating temperature. Actively cooled $\mathrm{W}$ samples were loaded under two conditions: (1) with pure $\mathrm{H}$ and (2) with a mix of 90 at.\% $\mathrm{H}$ and 10 at.\% $\mathrm{He}$ (flux $2 \times 10^{21} / \mathrm{m}^{2} \mathrm{~s}$ ). The applied $10 \mathrm{MW} / \mathrm{m}^{2}$ thermal load resulted in surface temperatures between $1773 \mathrm{~K}$ (1500 $\left.{ }^{\circ} \mathrm{C}\right)$ and $2273 \mathrm{~K}\left(2000{ }^{\circ} \mathrm{C}\right)$ depending on the sample design. Pulse durations of $30 \mathrm{~s}$ were used to achieve particle fluences up to $3 \times 10^{25}$ atoms $/ \mathrm{m}^{2}$ under stationary temperature conditions. All tested materials were completely recrystallized after less than $1 \mathrm{~h}$ loading. For 
both surface temperatures, $1773 \mathrm{~K}\left(1500{ }^{\circ} \mathrm{C}\right)$ and $2273 \mathrm{~K}\left(2000{ }^{\circ} \mathrm{C}\right)$, a substantial grain growth was observed. The initial anisotropic grain orientation of the materials disappeared in the samples heated to $2273 \mathrm{~K}\left(2000{ }^{\circ} \mathrm{C}\right)$. Grain growth and physical sputtering were identified as the only surface modification processes of the pure hydrogen loaded materials. Thermally induced cracks into the bulk material did not occur. In the case of the mixed $\mathrm{H} / \mathrm{He}$ loading, the $10 \% \mathrm{He}$ fraction dominated the surface morphology changes. A high number of voids were identified up to a depth of about $1 \mu \mathrm{m}$ below the surface. Due to the porous surface structure the effective armor surface is reduced (compared to a plane surface). Therefore, an enhanced erosion rate of the plasma facing material had to be taken into consideration for the operating conditions of a DEMO power plant. After validation by further tests, this would be a very important result with a high impact on the power plant design.

\subsection{First wall shield materials}

The use of self-passivating tungsten alloys as armor material of the first wall of a fusion power reactor may be advantageous to safety. Previous studies have demonstrated the good performance of the system $\mathrm{W}-\mathrm{Cr}-\mathrm{Si}$ [23]. Thin films of such alloys showed a strongly reduced oxidation rate compared to pure tungsten. However, the formation of brittle tungsten silicides may be disadvantageous for the powder metallurgical production of bulk $\mathrm{W}-\mathrm{Cr}-\mathrm{Si}$ alloys if a good workability is needed. Screening tests have been carried out with a variety of alloys (W-Cr14-Ti2, W-Cr18-Ti2, W-Cr16-Zr9, W-Hf17-Ta15, W-Hf32-Ti2, W-Ta12-Ti2, W-Ta12-Zr5, W-Zr2-Ti1, W-Y7-Cr3, W-Y24-Cr2) to identify suitable silicon-free alloys with distinguished self-passivation and a potentially good workability. Of all tested systems, $\mathrm{W}-\mathrm{Cr}-\mathrm{Ti}$ alloys showed the most promising results. The oxidation rate was even lower than that of the WCr12Si8 alloys (compositions are given in weight percent), that is, the improvement was about four orders of magnitude compared to pure tungsten. This performance could be preserved even if the content of alloying $\mathrm{Cr}$ was reduced from $18 \mathrm{wt} . \%$ to 14 wt.\%. In addition to thin films, bulk alloys (e.g., WCr10Si10, WCr12Ti2.5) have been manufactured by powder metallurgy (mechanical alloying + HIP), obtaining a nearly perfect density [24,25]. In the ongoing program, the focus is on mockup fabrication using these materials as a shield.

Vacuum plasma-sprayed tungsten (VPS-W) is a coating candidate in the design of first wall components which are expected to face a moderately high heat-flux [26]. It combines the advantages of $\mathrm{W}$ as first wall material with the ability to coat large areas and the possibility to repair damaged parts. In this context, tomographic bulk data of the full coating system (VPSW joined to a EUROFER steel substrate) can greatly help to improve the understanding of the complex mechanisms governing heat transfer, damage, and failure of the coating. Synchrotron-radiation computerized microtomography offers the advantage of nondestructive imaging of relatively large material regions at high spatial resolution and can be used to feed micromechanical models. Details of the experiment are reported in [27-29]. A tomographic reconstruction of the interlayer region was extracted from a cylindrical sample (diameter $0.6-1 \mathrm{~mm}$ ). In the interlayer, W-particles are surrounded by the steel matrix. A relatively high porosity was observed, in particular at the interface to VPS-W (up to 35 vol.\%). Its origin, however, is still unclear, and further investigations are required to understand the evolution of interfacial and bulk porosity during deposition, operation, and sample preparation. 


\section{Materials science and modeling}

As already mentioned, up to now, only Re (and probably Ir) is known to form a ductile tungsten alloy. The intrinsic brittleness of tungsten is primarily due to the high activation energy of screw dislocation glide. Furthermore, radiation damage data - especially under divertor operation conditions - are very rare. Therefore, the main objective for this research line is to assist and guide the materials development process. The basic idea is to identify the origin of the extreme brittleness of tungsten and to explore a range of potential ductilization treatments. In parallel, modeling of radiation effects, i.e., point defects and $\mathrm{He} / \mathrm{H}$ accumulation, in bulk and subsurface has to be performed.

But the most striking question still is: How does tungsten behave under high neutron doses and after significant $\mathrm{He} / \mathrm{H}$ load?

\subsection{Plasticity studies}

It is well known that the impurity content (e.g., of $\mathrm{S}, \mathrm{P}, \mathrm{O}, \mathrm{C}$ ) influences the fracture behavior of tungsten. However, as one is dealing with different production routes - especially in case of material produced for scientific purposes - it is not easy to distinguish between effects of grain size, grain shape, impurity content, etc. on mechanical properties. Nevertheless, assuming a strong decrease of fracture toughness for impure materials induced by low solubility of interstitial atoms and grain boundary segregation, vast regions of intercrystalline fracture would be expected. In a recent study, the fracture surfaces of ten different tungsten materials, differing in processing route and thus in grain size, grain aspect ratio, and grain boundary impurity concentrations, were investigated using Auger electron spectroscopy and scanning electron microscopy [30]. The manufacturing conditions are: sintered, hipped, rolled, recrystallized, deformed by HPT and a high purity single crystal, which was HPTdeformed and annealed at different temperatures, resulting in different grain sizes. As expected, the impurity concentration decreases with decreasing grain size. All samples were fractured at room temperature, i.e., in the brittle regime of tungsten. Combining all data on the ratio of inter- vs. transcrystalline fracture, grain shape, and grain size leads to inconsistencies when postulating a pronounced grain boundary weakening for high impurity contents. The fracture behavior is much more dependent on the microstructure - on the grain aspect ratio, grain size, its distribution, and dislocation density. What has to be emphasized is that the observation of large amounts of intercrystalline fracture does not automatically indicate impurity induced embrittlement.

It is known that tungsten features an anisotropic fracture behavior in the presence of elongated grains, e.g., after rolling, forging, and deformation by HPT [19,31]. Additionally, the fracture resistance may increase with crack propagation, which implies that it is not always possible to characterize the material's toughness with a single value such as plane strain fracture toughness $K_{\mathrm{IC}}$ or critical energy release rate $G_{\mathrm{IC}}$. Instead, the whole crack resistance curve ( $R$-curve) - describing the dependency of fracture resistance vs. crack propagation has to be given. The initial part of the $R$-curve is governed by processes in the immediate vicinity of the crack tip, e.g., formation of selected cleavage planes, fracture of selected grain boundaries, or tunneling of the crack to the next grain boundary. In a later stage of testing and in case of predominant intercrystalline failure, the increase of the $R$-curve depends on 
appearing crack bridges, which connect the crack flanks and fail by plastic deformation, thus consuming more energy and leading to an extrinsic toughening. Experimental details are given in [19]. There, temperature-dependent fracture experiments using technically pure tungsten featuring recrystallized (globular) and deformed (elongated grains) microstructures are described. $R$-curve behavior was found in both cases. Furthermore, the appearance is independent of testing direction, i.e., independent of the dominance of intercrystalline or transcrystalline fracture. However, the increase of the $R$-curve is rather steep for transcrystalline fracture, compared to the intercrystalline one. In addition, predeformation of the material and higher test temperatures increase the fracture resistance, i.e., the starting values of the $R$-curves are higher. For pre-deformation, the initial values of the $R$-curve are higher; for higher testing temperatures, the $R$-curve behavior is more pronounced $[32,33]$.

\subsection{Simulation}

It has been realized that the plastic behavior and mechanical properties of crystalline materials strongly depend on the properties of dislocations. For body-centered cubic (bcc) crystal structures, the low temperature plasticity is governed mainly by the $1 / 2 \mathrm{~h}<111>$ screw dislocations due to their low mobility as compared to edge segments. Important features including dislocation-core structure, Peierls stress, slip plane, and dislocation kinks have been obtained for many bcc metals from computer simulations [34,35]. Based on densityfunctional theory (DFT), the $1 / 2<111>$ screw dislocations in $\mathrm{W}$ and its alloys are investigated to understand the basic mechanism of plastic deformation [36]. The dislocation-core structure in pure W is optimized using both Quantum-ESPRESSO package and VASP code, and a symmetric or non-degenerate core is revealed. The critical stress, Peierls stress, to move the dislocation in the crystal is calculated and the dislocation is found to slip on $\{110\}$ planes. When alloying with $\mathrm{Re}$, the dislocation gradually changes to an asymmetric or degenerate core structure; accordingly the Peierls stress is lowered, and the dislocation slips in a zig-zag manner on different $\{110\}$ planes, which overall results in a movement on $\{112\}$ planes. These results agree well with the Re ductilizing effect. Other alloying in $\mathrm{W}$ including $\mathrm{Ti}, \mathrm{V}$, and $\mathrm{Ta}$ does not induce big changes to the dislocation-core structure. Possible predictions for this transition of core symmetry attract more research interests. First, the $\{110\} \mathrm{Y}$-surfaces for W-Ta and W-Re alloys are evaluated, and both exhibit the elliptical distortion. Hence, the core structure is not directly reflected from the $\mathrm{Y}$-surface. Second, the interrow potentials extracted from displacing one row out of a set of [111] atomic rows are examined [37]. It is found that both types of core symmetry can be generated correctly for different alloys using the interrow potential, but the shape of the potential curve remains almost the same when alloying $\mathrm{Re}$ in $\mathrm{W}$. Therefore, no criterion for prediction of the core symmetry has been found up to now and the symmetry needs to be determined from the geometry optimization directly.

The ideal tensile strengths in the [001] direction of bcc tungsten pure crystal and $\mathrm{W}$ alloys (W-Re, W-Ta, and $\mathrm{W}-\mathrm{V}$ ) have been investigated using first-principles total energy methods based on the DFT with the generalized gradient approximation and by using the CPMDs (Car-Parrinello Molecular Dynamics) code. The validity of the numerical model has been extensively checked by computing physico-chemical properties of pure $W$ and its alloys. Then, a systematic procedure has been developed to perform tensile tests and the characterization of mechanical properties. Initial results with low concentration of substitutional defects (about $2 \%$ ) reveal the ability of $\mathrm{Re}$ and $\mathrm{Ta}$ to decrease sensibly both 
bulk modulus and ideal tensile strengths with respect to pure $\mathrm{W}$. On the contrary $\mathrm{W}-\mathrm{V}$ alloys show higher values of ideal tensile strengths.

A rate equation simulation ( $R E$ ) method was developed for hydrogen implantation into $W$, where all the defect concentrations, intrinsic and irradiation-induced ones, are solved together with the hydrogen present in the sample. The numerous material parameters for the $\mathrm{RE}$ were taken from the literature [38-40]. For validating the RE code, an exemplary system of 5,15 , and $30 \mathrm{keV}$ deuterium (D) implantation into $W$ was analyzed with the RE method and the results were compared with corresponding experimental results [41]. The implantation time, dose, and temperature used in the RE simulations were taken from the experimental set-up. The validated RE code is suitable for simulating hydrogen implantations into $\mathrm{W}$ with fluences below the blistering threshold. RE simulations of a $5 \mathrm{keV} / \mathrm{D}$ implantation were compared with the experimental $D$ concentration. An excellent agreement could be seen with the RE simulated and experimentally obtained $D$ profile. According to RE, over $90 \%$ of the retained $\mathrm{D}$ is trapped at mono-vacancies (V1) after the implantation. The simulation shows that immediately after the implantation, the solute $D$ concentration decreases rapidly to zero. The slow decrease in retained $D$ is the detrapping of the sixth $D$ from the vacancies (trapping energy $0.61 \mathrm{eV}$ ). This post-implantation effect has been seen experimentally, for example, by Garcia-Rosales et al. [42] and Pisarev et al. [43], where the observed $D_{2}$ desorption from the sample surface resembles the present simulated $D$ flux to surface.

The formation of voids in $800 \mathrm{keV}{ }^{3} \mathrm{He}$ implanted tungsten further annealed has been modeled using an object kinetic Monte Carlo (OKMC) code [44]. These simulations underline the role of the He atoms in the track region (700 nm from the surface), which despite their small amount act as germs for the formation of nanovoids [45]. The parameterization of the code is based on first principles calculations [44]. The implanted ions flux is modeled using cascade debris calculated by MARLOWE (a code based on binary collision approximation) [46]. This work includes experimental investigations on the nanovoid formation using positron annihilation spectroscopy [47] and the simulation conditions have been chosen to model these experiments. Different fluences (implanted at $300 \mathrm{~K}$ ) have been investigated, ranging from $10^{13}$ to $5 \times 10^{16}$ ions $\mathrm{cm}^{2}$. Good agreement with the experimental results has been obtained because the model takes into account the diffusion of self-interstitial atoms (SIAs) and $\mathrm{He}$ atoms which takes place at the implantation temperature $(300 \mathrm{~K})$, and the resulting amount of recombination. The isochronal annealing sequences start between $300 \mathrm{~K}$ and 900 $\mathrm{K}$. Despite its simplicity, the OKMC model agrees with the experimentally estimated number of vacancies in the nanovoids (above 30 vacancies). Furthermore, as observed experimentally, the number of vacancies in the nanovoids decreases when the fluence increases. The role of the He atoms is underscored by the large amount of He-vacancy clusters as compared with the number of pure vacancy clusters. Furthermore, it was shown that without the He atoms, the trends in the evolution of the nanovoid size vs. fluence are not reproduced.

The migration of small He clusters and the influence of impurities have been investigated using density functional calculations and the VASP code. The results indicate that small He clusters are mobile. Furthermore, it was found that $2 \mathrm{He}$ clusters have a $1 \mathrm{D}$ motion along the $<111>$ direction at low temperatures $(150-600 \mathrm{~K})$. When the temperature increases, the $2 \mathrm{He}$ cluster can change $<111>$ direction, and the higher the temperature, the more the motion varies in three dimensions. Furthermore, it was found that $2 \mathrm{He}$ clusters have a $1 \mathrm{D}$ motion along the $<111>$ direction at low temperatures (150-600 K). The binding energies of selected 
impurities with $\mathrm{He}$ and small He clusters were determined. It was seen that most of the investigated substitutional impurities can trap He atoms as well as small He clusters. The exception is $\mathrm{Re}$, and we anticipate thus that the introduction of Re, either to improve the mechanical properties or because of transmutation, will not affect He transport in W.

Furthermore, comprising DFT studies gave rise to the experimentally made observation that $\mathrm{W}-\mathrm{Ta}$ and $\mathrm{W}-\mathrm{V}$ alloys are brittle (even more brittle that pure tungsten). But the studies show also that such solid solutions could have much better irradiation properties $[48,49]$. Therefore, the programme continues with its previous strategy to evaluate new tungsten materials for both applications (structural and armor) prior to a final assessment.

Materials bombarded by neutrons from a fusion plasma will undergo non-elastic nuclear reactions, whose cross section ('reaction probability') is strongly dependent on the incident neutron energy. Using the neutron fluxes and energy-spectra predicted by a neutrontransport code (MCNP), inventory calculations provide quantitative estimates of the concentrations of impurities generated - transmutation products. In $\mathrm{W}$, the production of impurities, such as $\mathrm{Re}, \mathrm{Ta}$, and Os, is fairly significant, for from a few thousand to tens of thousands of atomic parts per million (appm) over a typical DEMO-like first-wall 5-year neutron exposure. Over such a timescale, this leads to $\mathrm{W}$ falling from 100 atomic\% initially, to less than 94 atom\%. Under the same conditions, other materials, by comparison, would hardly be transmuted (burnt-up) at all; for instance, in pure Fe, the total concentration of all transmutation products after 5 years is only around 1 atom\%. Thus, it is conceivable that components constructed of $\mathrm{W}$, with its relatively high transmutation rates, would experience measurable changes in mechanical and structural properties. Perhaps the only good news as far as $\mathrm{W}$ is concerned is that helium is generated in relatively modest quantities, typically only reaching a few $10 \mathrm{~s}$ of appm over the expected normal lifetime of first wall fusion-reactor components. However, several of the materials under discussion for $\mathrm{W}$-alloys, such as $\mathrm{Ti}$ and $\mathrm{V}$, produce an order of magnitude more He compared to $\mathrm{W}$ (or Re or $\mathrm{Ta}$ ), and so the actual ability of $W$ and $W$-alloys to withstand the effects of the embrittlement mechanisms activated by He must be carefully considered [50].

\section{Summary and outlook}

The long-term goal of the EFDA program on divertor materials is

to provide structural and functional materials together with the necessary production and fabrication technology for future fusion reactors beyond ITER. While fabrication issues are far advanced and well investigated, the most critical part of the programme is still the development of a material for structural divertor parts. Joining of tungsten materials is possible, but design routes, cost, and low-activation criteria have most probably to be redefined for brazing materials. The simulation of possible armor materials is well established by the use of the JUDITH and GLADIS facilities. The results clearly show that the calculated sputtering rates might be too low compared to the real in-service conditions. A complete picture of the irradiation performance of tungsten materials is not yet available. But for further, more specific designs at least basic irradiation damage data have to be produced. This, together with the aforementioned issues, should be on top of the priority list of fusion material programmes, in general. 


\section{Acknowledgement}

This work, supported by the European Communities, was carried out within the framework of the European Fusion Development Agreement. The views and opinions expressed herein do not necessarily reflect those of the European Commission.

\section{References}

[1] J. Pamela, A. Bécoulet, D. Borba, J.-L. Boutard, L. Horton, D. Maisonnier, Fusion Eng. Des. 84 (2009) 194-204.

[2] D. Maisonnier, D. Campbell, I. Cook, L. Di Pace, L. Giancarli, J. Hayward, A. Li Puma, M. Medrano, P. Norajitra, M. Roccella, P. Sardain, M.Q. Tran, D. Ward, Nucl. Fusion 47 (2007) 1524-1532.

[3] P. Norajitra, S.I. Abdel-Khalik, L.M. Giancarli, T. Ihli, G. Janeschitz, S. Malang, I.V. Mazul, P. Sardain, Fusion Eng. Des. 83 (2008) 893-902.

[4] G. Janeschitz, J. Nucl. Mater. 290-293 (2001) 1.

[5] H. Bolt, V. Barabash, G. Federici, J. Linke, A. Loarte, J. Roth, K. Sato, J. Nucl. Mater. 307-311 (2002) 43.

[6] K. Wittlich, T. Hirai, J. Compan, N. Klimov, J. Linke, A. Loarte, M. Merola, G. Pintsuk, V. Podkovyrov, L. Singheiser, A. Zhitlukhin, Fusion Eng. Des. 84 (2009) 1982.

[7] T. Hirai, G. Pintsuk, J. Linke, M. Batilliot, J. Nucl. Mater. 390-391 (2009) 751.

[8] J. Roth, E. Tsitrone, A. Loarte, Th. Loarer, G. Counsell, R. Neu, V. Philipps, S. Brezinsek, M. Lehnen, P. Coad, Ch. Grisolia, K. Schmid, K. Krieger, A. Kallenbach, B. Lipschultz, R. Doerner, R. Causey, V. Alimov, W. Shu, O. Ogorodnikova, A. Kirschner, G. Federici, A. Kukushkin, EFDA PWI Task Force, ITER PWI Team, Fusion for Energy, ITPA SOL/DIV, J. Nucl. Mater. 390-391 (2009) 1.

[9] M. Rieth, J.L. Boutard, S.L. Dudarev, T. Ahlgren, S. Antusch, N. Baluc, M.-F. Barthe, C.S. Becquart, L. Ciupinski, J.B. Correia, C. Domain, J. Fikar, E. Fortuna, C.-C. Fu, E. Gaganidze, T.L. Galán, C. García-Rosales, B. Gludovatz, H. Greuner, K. Heinola, N. Holstein, N. Juslin, F. Koch, W. Krauss, K.J. Kurzydlowski, J. Linke, Ch. Linsmeier, N. Luzginova, H. Maier, M.S. Martínez, J.M. Missiaen, M. Muhammed, A. Muñoz, M. Muzyk, K. Nordlund, D. Nguyen-Manh, P. Norajitra, J. Opschoor, G. Pintsuk, R. Pippan, G. Ritz, L. Romaner, D. Rupp, R. Schäublin, J. Schlosser, I. Uytdenhouwen, J.G. van der Laan, L. Veleva, L. Ventelon, S. Wahlberg, F. Willaime, S. Wurster, M.A. Yar, J. Nucl. Mater. 417 (2011) 463.

[10] J. Reiser, M. Rieth, B. Dafferner, S. Baumgärtner, R. Ziegler, A. Hoffmann, Fusion Eng. Des. (2011), http://dx.doi.org/10.1016/j.fusengdes.2011.07.011.

[11a] S. Antusch, P. Norajitra, V. Piotter, H.-J. Ritzhaupt-Kleissl, L. Spatafora, Fusion Eng. Des. 86 (2011) 1575-1578;

[11b] T. Weber, J. Aktaa, Fusion Eng. Des. 86 (2011) 220-226; 
[11c] T. Weber, M. Härtelt, J. Aktaa, Eng. Fract. Mech., in press.;

[11d] J. Matejícek, H. Boldyryeva, V. Brozek, E. Cizmárová, Z. Pala, Tungsten-steel composites and FGMs produced by hot pressing, in: Proc. 21st International Conference on Metallurgy and Materials METAL, Brno, 2012 (paper no. 177);;

[11e] J. Matejícek, P. Chráska, J. Linke, J. Therm. Spray Technol. 16 (2007) 64-83;

[11f] J. Matejicek, V. Weinzettl, E. Dufkova, V. Piffl, V. Perina, Acta Technol. CSAV 51 (2) (2006) 179-191;

[11g] H. Greuner, H. Bolt, B. Böswirth, S. Lindig, W. Kühnlein, T. Huber, K. Sato, S. Suzuki, Fusion Eng. Des. 75-79 (2005) 333-338;

[11h] T. Kavka, J. Matejícek, P. Ctibor, M. Hrabovský, J. Therm. Spray Technol. 21 (3-4) (2012) 695-705.

[12a] M. Rieth, A. Hoffmann, Int. J. Refract. Met. Hard Mater. 28 (2010) 679;

[12b] Erik Lasser, Wolf-Dieter Schubert, Tungsten, Kluewer Academic/Plenum Publishers, 1998;

[12c] W. Stephen, Yih, Tungsten, Plenum Press, New York, 1979;

[12d] T.E. Tietz, J.W. Wilson, Behaviour and Properties of Refractory Metals, (1965) ISBN: 0713131470.

[13] L Veleva, Contribution to the production and characterization of $\mathrm{W}-\mathrm{Y}, \mathrm{W}-\mathrm{Y}_{2} \mathrm{O}_{3}$ and $\mathrm{W}-$ TiC materials for fusion reactors, thesis EPFL no. 4995, 2011.

[14] M. Battabyal, R Schäublin, P. Spätig, M. Walter, M. Rieth, N. Baluc, Microstructure and mechanical properties of $\mathrm{a} \mathrm{W}-2 \mathrm{wt} . \% \mathrm{Y}_{2} \mathrm{O}_{3}$ composite produced by sintering and hot forging, this issue.

[15] M.A. Yar, S. Wahlberg, H. Bergqvist, H.G. Salem, M. Johansson, M. Muhammed, J. Nucl. Mater. 408 (2011) 129.

[16] A.G. Evans, Acta Mater. 45 (1) (1997) 23-40.

[17] V. Livramento, D. Nunes, J.B. Correia, P.A. Carvalho, R. Mateus, K. Hanada, N. Shohoji, H. Fernandes, C. Silva, E. Alves, Tungsten-tantalum composites for plasma facing components, Materials for Energy, ENMAT2010, Karlsruhe, Germany, 4-8 July 2010.

[18] E. Gaganidze, D. Rupp, J. Nucl. Mater. (submitted for publication).

[19] D. Rupp, S.M. Weygand, Philos. Mag. 90 (2010) 4055-4069.

[20] R. Duwe, W. Kühnlein, M. Münstermann, in: Proc. 18th SOFT, Karlsruhe, Germany, 1994 (Fusion Technology (1994) 335).

[21] H. Greuner, H. Bolt, B. Böswirth, S. Lindig, W. Kuhnlein, T. Huber, K. Sato, S. Suzuki, Fusion Eng. Des. 75 (2005) 333.

[22] H. Greuner, B. Böswirth, J. Boscary, P. McNeely, J. Nucl. Mater. 367-370 (2007) 1444. 
[23] F. Koch, S. Köppl, H. Bolt, J. Nucl. Mater. 386-388 (2009) 572.

[24] F. Koch, U. Auzmendi, J. Brinkmann, P. López-Ruiz, N. Ordás, S. Lindig, M. Balden, C. García-Rosales, Ch. Linsmeier, Oxidation behaviour of self-passivating tungsten alloys - comparison of thin films and bulk material, this issue.

[25] P. López-Ruiz, N. Ordás, I. Iturriza, F. Koch, C. García-Rosales, Powder metallurgical processing of self-passivating tungsten alloys for fusion first wall application, this issue.

[26] J. Matejícek, P. Chráska, J. Linke, J. Therm. Spray Technol. 16 (2007) 64.

[27] A. Zivelonghi, Thermomechanical behaviour of two heterogeneous tungsten materials via 2D and 3D image-based FEM, PhD thesis, Technische Universität München, 2011.

[28] H. Bolt, V. Barabash, W. Krauss, et al., J. Nucl. Mater. 329-333 (2004) 66-73.

[29] H. Greuner, H. Bolt, B. Böswirth, S. Lindig, W. Kühnlein, T. Huber, Fusion Eng. Des. 75-79 (2005) 333.

[30] B. Gludovatz, S. Wurster, T. Weingärtner, A. Hoffmann, R. Pippan, Philos. Mag. 91 (2011) 3006-3020.

[31] S. Wurster, B. Gludovatz, A. Hoffmann, R. Pippan, J. Nucl. Mater. 413 (2011) 166-176.

[32] B. Gludovatz, S. Wurster, A. Hoffmann, R. Pippan, Influence of deformation, microstructure and temperature on the fracture resistance of tungsten, in preparation.

[33] B. Gludovatz, S. Wurster, A. Hoffmann, R. Pippan, A study into the crack propagation resistance of pure tungsten, Eng. Fract. Mech. (2012). http://dx.doi.org/10.1016/j.engfracmech.2012.07.021.

[34] V. Vitek, Philos. Mag. 84 (2004) 415.

[35] L. Ventelon, F. Willaime, P. Leyronnas, J. Nucl. Mater. 386 (2009) 26.

[36] L. Romaner, C. Ambrosch-Draxl, R. Pippan, Phys. Rev. Lett. 104 (2010) 195503.

[37] H. Li, S. Wurster C. Motz, L. Romaner, C. Ambrosch-Draxl, R. Pippan, Acta Mater. (submitted for publication).

[38] K. Heinola, T. Ahlgren, J. Appl. Phys. 107 (2010) 113531.

[39] K. Heinola, T. Ahlgren, K. Nordlund, J. Keinonen, Phys. Rev. B. 82 (2010) 094102.

[40] T. Ahlgren, K. Heinola, N. Juslin, A. Kuronen, J. Appl. Phys. 107 (2010) 033516.

[41] K. Heinola, T. Ahlgren, E. Vainonen-Ahlgren, J. Likonen, J. Keinonen, Phys. Scripta T128 (2007) 91.

[42] C. Garcia-Rosales, P. Franzen, H. Plank, J. Roth, E. Gauthier, J. Nucl. Mater. 233-237 (1996) 803.

[43] A.A. Pisarev, I.D. Voskresensky, S.I.J. Porfirev, Nucl. Mater. 313-316 (2003) 604. 
[44] C.S. Becquart, C. Domain, U. Sarkar, A. Debacker, M. Hou, J. Nucl. Mater. 403 (2010) 75.

[45] A. Debacker, C.S. Becquart, M.F. Barthe, P.E. Lhuillier, in preparation.

[46] M. Hou, C. Ortiz, C.S. Becquart, C. Domain, U. Sarkar, A. Debacker, J. Nucl. Mater. 403 (2010) 89.

[47] A. Debelle, M.F. Barthe, T. Sauvage, J. Nucl. Mater. 376 (2) (2008) 216.

[48] D. Nguyen-Manh, M. Muzyk, K.J. Kurzydlowski, N.L. Baluc, M. Rieth, S.L. Dudarev, Key Eng. Mater. 465 (2011) 15-20.

[49] M. Muzyk, D. Nguyen-Manh, K.J. Kurzydłowski, N.L. Baluc, S.L. Dudarev, Phys. Rev. B 84 (2011) 104115.

[50] M.R. Gilbert, J.-C.h. Sublet, Nucl. Fusion 51 (2011) 043005. 